\title{
Role of Cytokines in the Pathogenesis of Non-Alcoholic Fatty Liver Disease
}

\author{
Subir Kumar Das $・$ V. Balakrishnan
}

Received: 24 September 2010/ Accepted: 7 February 2011/Published online: 7 April 2011

(C) Association of Clinical Biochemists of India 2011

\begin{abstract}
A number of factors are linked with non-alcoholic fatty liver diseases (NAFLD), a condition that ranges from clinically benign fatty liver to its more severe form, non alcoholic steatohepatitis (NASH). In this study, we evaluated the role of cytokines secreted from adipose tissue in the pathogenesis and progression of NAFLD. We also compared anthropometric profile, lipid profile and insulin resistance data in 105 NAFLD patients with 77 normal subjects. These subjects showed a normal serum albumin level, prothrombin time and renal function but elevated aminotransferases. Predisposing factors were diabetes mellitus (35\%), overweight (56\%) and hyperlipidemia $(44 \%)$. Insulin resistance (IR), determined by homeostasis model assessment (HOMA) was confirmed in $70 \%$ patients with NAFLD and $42 \%$ patients fulfilled the minimum criteria for insulin resistance syndrome (IRS). NAFLD patients showed elevated levels of pro-inflammatory cytokines tumor necrosis factor (TNF)- $\alpha$, and interleukin (IL)6 , while anti-inflammatory cytokines IL-4 level decreased and IL-10 level remain unchanged; however, TGF- $\beta 1$ level elevated significantly compared to normal subjects. While insulin level and HOMA-IR both were significantly
\end{abstract}

Electronic supplementary material The online version of this article (doi:10.1007/s12291-011-0121-7) contains supplementary material, which is available to authorized users.

\section{S. K. Das $(\bowtie)$}

Department of Biochemistry, College of Medicine and JNM

Hospital, WBUHS, Kalyani, Nadia, India

e-mail: drsubirkdas@gmail.com

V. Balakrishnan

Department of Gastroenterology, Amrita Institute of Medical

Sciences, Ponekkara P.O., Cochin 682 041, Kerala, India positively correlated with BMI, waist-to-hip ratio, total cholesterol, VLDL-cholesterol, triglyceride and TGF- $\beta 1$; glucose, IL-6 and TNF- $\alpha$ levels were significantly positively correlated with HOMA-IR only. In conclusion, proinflammatory cytokines play an important link between metabolic and liver disorders in the fat accumulation, and thereby cause IR, inflammation and liver fibrosis.

Keywords Insulin resistance - Interleukin-6 .

Non-alcoholic fatty liver disease $\cdot$ Transforming growth factor beta $\cdot$ Tumor necrosis factor-alpha

\section{Introduction}

Nonalcoholic fatty liver disease (NAFLD) is the hepatic manifestation of the metabolic syndrome that can vary from benign steatosis to end-stage liver disease, non alcoholic steatohepatitis (NASH) [1]. NASH (Fig. 1) is characterized by morphological features indistinguishable from alcoholic liver disease in individuals who do not consume significant amount of alcohol [2]. The increased prevalence of diabetes, obesity, hypertension, hypertriglyceridemia and/or hypercholesterolemia in the general population is considered to be the most common cause for NAFLD [3]. NASH is also related with a number of other conditions such as elevated lipoprotein in blood, jejunal bypass surgery, parenteral nutrition, drugs, enzymes like$\alpha 1$-antitrypsin deficiency, excessive bacterial growth, and exposure to environmental toxic chemicals [4].

Although the prevalence of NASH appears to be increasing, the etiopathogenesis remains poorly understood. Interestingly, autopsy data indicate that NASH is at least 6 times more prevalent in obese individuals compared with lean subjects [5]. Obesity increases adipose tissue 


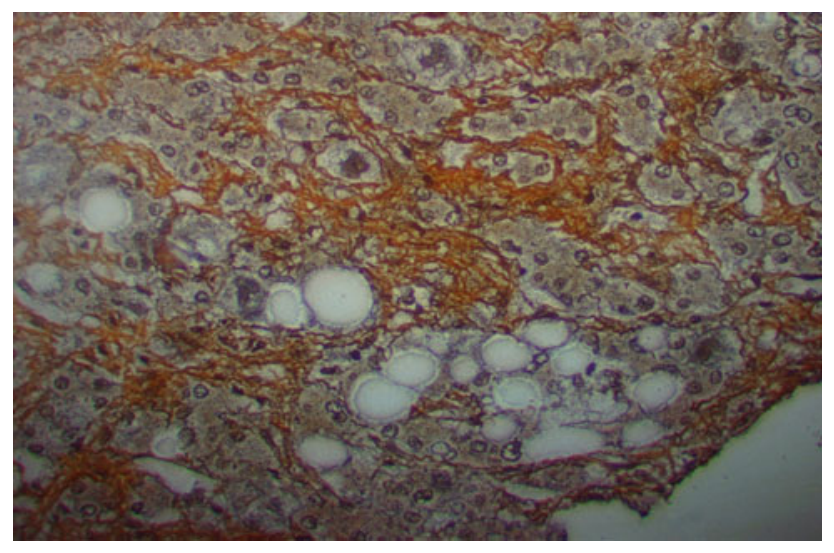

Fig. 1 Steatosis with perisinusoidal fibrosis

mass. It has long been known that adipose tissue is a source of free fatty acids that are delivered to the liver and a depot for triglycerides that are synthesised by hepatocytes and released into the blood. Fat produces hormones that regulate metabolism in other tissues, as well as fat itself. Fat is also a source of neurotransmitters. In addition, adipocytes produce immunomodulatory cytokines [6].

Hepatic steatosis is thought to represent the 'first' step [5] of 'two hit' hypothesis, and the 'second' step is the process that promotes the inflammation, fibrosis and necrosis associated with NASH [4, 7-10]. Evidence suggests that endotoxin-mediated cytokines are important mediators of hepatic steatohepatitis [11]. Cytokines are classified as T helper 1 (Th1) and T helper 2 (Th2) subtypes. The main proinflammatory Th1 cytokines are tumor necrosis factor-alpha (TNF- $\alpha$ ), interleukin (IL)-1, IL-6 and interferon; whereas the main Th2 anti-inflammatory cytokines are IL-4 and IL-10. In general, Th1 cytokines induce Th1 cytokines and inhibit Th2 cytokine production and vice versa [12]. Normally, there is a balance between proinflammatory and anti-inflammatory cytokines [13].

Therefore, we evaluated the role of cytokines secreted from adipose tissue such as TNF- $\alpha$, IL- 6 , transforming growth factor-beta (TGF- $\beta$ )-1 in the pathogenesis and progression of NAFLD in this study. We also compared anthropometric profile, lipid profile, insulin resistance data and anti-inflammatory cytokines in NAFLD patients with normal subjects.

\section{Patients and Methods}

\section{Chemicals}

Laboratory routine test kits from Roche Diagnostics, Meylan, France were used. Insulin, IL-4, IL-6, IL-10, TNF$\alpha$ and TGF- $\beta 1$ ELISA kits were purchased from Bender Med Systems, Austria.

\section{Subject Selection}

Selected patients who had visited the Gastroenterology Department of the Amrita Institute of Medical Sciences, Cochin, were referred for the assessment of abnormal liver function tests (LFT) or hepatic steatosis detected by ultrasonography. The NAFLD patients were identified on the basis of oral questionnaire, laboratory investigations, clinical findings and ultrasound/CT scan imaging or biopsy, where applicable. These subjects had a normal serum albumin level, prothrombin time (Table 2) and renal function (Table 2) but elevated liver aminotransferases (Table 2). Current and past daily alcohol intake was less than $40 \mathrm{~g}$ per week for all patients and all regular alcohol consumers were excluded from this group.

The disorders such as secondary causes of steatohepatitis, drug induced liver disease, alcoholic liver disease, viral hepatitis, autoimmune hepatitis, primary biliary cirrhosis, sclerosing cholangitis, $\alpha_{1}$-antitrypsin deficiency, hemochromatosis, Wilson's disease and biliary obstruction were excluded. Other exclusion criteria were recent gastrointestinal surgery, older age ( $>65$ years), pregnancy, suffering from malignancy or under any kind of medication. The study protocol was approved by the Institutional ethics committee according to the ethics guidelines of the 1975 Declaration of Helsinki, and all patients gave their written informed consent to the study.

Subjects who had visited the Amrita Institute of Medical Sciences, Cochin, for routine health check-up programmes without any specific problem and with no abnormality in the clinical and laboratory findings were considered 'normal'. NAFLD group consists of 105 patients (89 male and 16 female) including 8 biopsy proven NASH patients.

\section{Methods}

A complete clinical history, including anthropometric measurements of the subjects was obtained. Anthropometric evaluation included measures of body mass index (BMI) and waist-to-hip ratio [WHR]). BMI was calculated as weight $(\mathrm{kg})$ divided by height $(\mathrm{m})$ squared, and WHR was defined as the waist circumference $(\mathrm{cm})$ divided by the hip circumference $(\mathrm{cm})$.

Fasting blood was collected, prior to medical intervention for the determination of biochemical parameters including glucose level, insulin level, lipid profile, liver function test, renal function test and cytokine estimation. Insulin, interleukins, TNF- $\alpha$ and TGF- $\beta 1$ levels in serum were estimated by ELISA following the manufacturer's instructions. Remaining biochemical parameters were estimated by conventional methods.

Insulin resistance was calculated by the homeostasis model (HOMA-IR) using the formula; HOMA-IR = fasting 
Table 1 Diagnostic criteria for IRS according to WHO consultation (1999)

$M$ male, $F$ Female

\begin{tabular}{ll}
\hline Component & Definition \\
\hline $\begin{array}{l}\text { Diabetes mellitus, impaired glucose tolerance, and/or insulin resistance } \\
\text { together with } 2 \text { or more of the following }\end{array}$ \\
BMI $\left(\mathrm{kg} / \mathrm{m}^{2}\right)$ & $\geq 30$ \\
Waist to hip ratio & $>0.9(\mathrm{M}),>0.85(\mathrm{~F})$ \\
Arterial pressure $(\mathrm{mm} \mathrm{Hg})$ & $\geq 140 / 90$ \\
Triglyceride $(\mathrm{mg} \%)$ & $\geq 150$ \\
HDL-cholesterol $(\mathrm{mg} \%)$ & $<35(\mathrm{M}),<39(\mathrm{~F})$ \\
Microalbuminuria & $\geq 20 \mu \mathrm{g} / \mathrm{min}$ \\
\hline
\end{tabular}

insulin $(\mu \mathrm{U} / \mathrm{ml}) \times$ plasma glucose $(\mathrm{mmol} / \mathrm{l}) / 22.5$ [14] Insulin resistance syndrome (IRS) was defined according to World Health Organization criteria (Table 1) [15, 16].

Except NASH patients, remaining NAFLD patients were classified into two subgroups according to degree of severity of fibrosis based on 6 variables as described elsewhere [17]: NAFLD fibrosis score $=-1.675+0.037 \times$ age $($ years $)+$ $0.094 \times$ BMI $\left(\mathrm{kg} / \mathrm{m}^{2}\right)+1.13 \times$ IFG/diabetes $($ yes $=1$, no $=0)+0.99 \times \quad$ AST/ALT ratio $-0.013 \times$ platelet $\left(\times 10^{9} / 1\right)-0.66 \times$ albumin $(\mathrm{g} / \mathrm{dl})$. The presence of fibrosis score between -1.455 and 0.676 was considered mild (I, $n=62$ ); and greater than 0.676 was considered moderate or significant (II, $n=35$ ) NAFLD. The results were compared with and 77 normal subjects (45 male and 32 female).

\section{Statistical Analysis}

Results are expressed as mean \pm SD (standard deviation). All data were analysed using the SPSS statistical package (version 11.0; SPSS Inc., Chicago, IL, USA). The association among biochemical and anthropometric characteristics was tested by Pearson correlation. The differences were considered significant at $P<0.05$.

\section{Results}

NAFLD patients showed significantly higher body mass index (BMI) and Waist-to-hip ratio compared to control group (Table 2), but no significant change was observed with severity of liver disease in any group (Table 2). Waist-to-hip ratio in NAFLD patients, and in particular in male patients was significantly higher compared to normal subjects (Tables 2, 3). NAFLD patients showed normal serum protein level, albumin level, prothrombin time (Table 2), renal function and electrolyte level (Table 2) but elevated uric acid and liver aminotransferases (Table 2) in this study.

In this study, diabetes mellitus was noted in $35 \%$ patients. Fasting insulin level was significantly higher in male and total NAFLD patients in comparison to normal subjects (Tables 2, 3), and its level elevated significantly with severity of the disease (Table 2). Though, fasting glucose level or insulin resistances (HOMA-IR) were significantly higher in NAFLD patients (Tables 2, 3), these did not change with severity of the disease (Table 2). While insulin level and HOMA-IR both were significantly positively correlated with BMI, waist-to-hip ratio, total cholesterol, VLDL-cholesterol, triglyceride and TGF- $\beta 1$ (Table 4); glucose, IL-6 and TNF- $\alpha$ levels were significantly positively correlated with HOMA-IR only (Table 4).

In this study, $44 \%$ patients showed hyperlipidemia (including 26\% hypercholesterolemia, and 30\% hypertriglyceridemia) and $56 \%$ patients were overweight according to WHO guideline (Table 1). However, when overweight determination was adjusted for Asians according to recommendations of several groups [16-18] overweight patients were $88 \%$. Cholesterol level was found significantly higher in both male and female patients in comparison to their respective normal subjects (Tables 2, 3), while VLDL-cholesterol and triglyceride levels were significantly higher in male and total NAFLD patients compared to normal male subjects (Tables 2, 3). However, lower HDL-cholesterol (<35 $\mathrm{mg} \%$ for male and $<39 \mathrm{mg} \%$ for female) (Table 1) level was observed in $31 \%$ NAFLD patients in this study.

While IL-4 level decreased significantly; IL-6, TNF- $\alpha$ and TGF- $\beta 1$ levels were significantly increased in NAFLD patients compared to normal subjects (Table 2). Moreover, IL-6, TNF- $\alpha$ and TGF- $\beta 1$ levels increased significantly with severity of NAFLD (Table 2).

\section{Discussion}

Most NAFLD patients in this study are asymptomatic with moderately elevated aminotransferase levels (Table 2). The vast majority of individuals with NAFLD are diagnosed incidentally during the course of assessment of unrelated symptoms or the associated metabolic syndrome [4]. NAFLD has been consistently associated with obesity (60-95\%), diabetes (28-55\%), and dyslipidemia (27-92\%) 
Table 2 Anthropometric and biochemical parameters of different stages of non-alcoholic fatty liver disease (NAFLD) patients and normal subjects

\begin{tabular}{|c|c|c|c|c|c|}
\hline & \multicolumn{4}{|c|}{ Non-alcoholic fatty liver disease } & \multirow{2}{*}{$\begin{array}{l}\text { Normal } \\
(n=77)\end{array}$} \\
\hline & $\begin{array}{l}\text { Mild fibrosis I } \\
(n=62)\end{array}$ & $\begin{array}{l}\text { Moderate fibrosis II } \\
(n=35)\end{array}$ & $\begin{array}{l}\text { NASH } \\
(n=8)\end{array}$ & $\begin{array}{l}\text { Total patients } \\
(n=105)\end{array}$ & \\
\hline Age (years) & $43.56 \pm 11.02$ & $40.06 \pm 7.44$ & $38.63 \pm 8.78$ & $42.02 \pm 9.9$ & $45.43 \pm 11.15$ \\
\hline BMI $\left(\mathrm{kg} / \mathrm{m}^{2}\right)$ & $24.83 \pm 2.33^{\mathrm{a}}$ & $25.81 \pm 2.23^{\mathrm{a}}$ & $27.11 \pm 3.18^{\mathrm{a}}$ & $25.33 \pm 2.44^{\mathrm{a}}$ & $22.6 \pm 1.32$ \\
\hline Waist/hip ratio & $1.03 \pm 0.04$ & $1.04 \pm 0.03^{\mathrm{b}}$ & $1.05 \pm 0.01^{\mathrm{a}}$ & $1.04 \pm 0.03^{\mathrm{b}}$ & $1.02 \pm 0.02$ \\
\hline Glucose $(\mathrm{mg} \%)$ & $112.2 \pm 36.3$ & $121.7 \pm 51.3^{\mathrm{a}}$ & $106.6 \pm 38.7$ & $115 \pm 41.9^{\mathrm{a}}$ & $92.1 \pm 12.3$ \\
\hline Insulin $(\mu \mathrm{U} / \mathrm{ml})$ & $11.75 \pm 1.76$ & $15.47 \pm 6.37^{\mathrm{ad}}$ & $18.42 \pm 6.77^{\text {adf }}$ & $13.5 \pm 4.81^{\mathrm{b}}$ & $10.69 \pm 1.73$ \\
\hline HOMA-IR & $3.21 \pm 1.12^{\mathrm{c}}$ & $4.52 \pm 2.1^{\mathrm{ad}}$ & $4.81 \pm 2.31^{\mathrm{a}}$ & $3.77 \pm 1.73^{\mathrm{a}}$ & $2.42 \pm 0.5$ \\
\hline Cholesterol (mg/dl) & $207.47 \pm 43.78^{\mathrm{a}}$ & $217.8 \pm 41.5^{\mathrm{a}}$ & $227.7 \pm 63.7^{\mathrm{a}}$ & $212.4 \pm 44.7^{\mathrm{a}}$ & $161.5 \pm 23.6$ \\
\hline HDL-cholesterol (mg/dl) & $41.9 \pm 10.5^{\mathrm{c}}$ & $40.1 \pm 9.9$ & $36.6 \pm 7.2$ & $40.9 \pm 10.1^{\mathrm{c}}$ & $45.4 \pm 9.4$ \\
\hline LDL-cholesterol (mg/dl) & $130.6 \pm 35.4$ & $143.3 \pm 42.2$ & $147.1 \pm 26.9$ & $136.1 \pm 37.6$ & $123.8 \pm 31.4$ \\
\hline VLDL-cholesterol (mg/dl) & $30.8 \pm 13.6$ & $41.1 \pm 20.6^{\mathrm{ae}}$ & $38.1 \pm 18.2^{\mathrm{b}}$ & $34.8 \pm 17.1^{\mathrm{a}}$ & $25.4 \pm 10.2$ \\
\hline Triglyceride (mg/dl) & $158.1 \pm 55$ & $201.2 \pm 69.4^{\mathrm{a}}$ & $194.6 \pm 30.1$ & $175.3 \pm 62^{\mathrm{a}}$ & $129.3 \pm 51.5$ \\
\hline Protein $(\mathrm{g} / \mathrm{dl})$ & $7.7 \pm 0.56$ & $7.6 \pm 0.56$ & $7.9 \pm 0.46$ & $7.68 \pm 0.56$ & $7.45 \pm 0.51$ \\
\hline Albumin (g/dl) & $4.5 \pm 0.45$ & $4.6 \pm 0.3$ & $4.7 \pm 0.46$ & $4.59 \pm 0.4$ & $4.42 \pm 0.42$ \\
\hline Total Bilirubin (mg/dl) & $0.94 \pm 0.57$ & $0.99 \pm 0.45$ & $1.07 \pm 0.45$ & $0.97 \pm 0.52$ & $0.81 \pm 0.33$ \\
\hline Direct Bilirubin (mg/dl) & $0.24 \pm 0.27$ & $0.25 \pm 0.12$ & $0.25 \pm 0.15$ & $0.25 \pm 0.22$ & $0.19 \pm 0.09$ \\
\hline AST (IU/l) & $52.7 \pm 14.5^{\mathrm{c}}$ & $63.1 \pm 20.3^{\mathrm{b}}$ & $78 \pm 22.3^{b}$ & $58 \pm 18.6^{\mathrm{b}}$ & $25.1 \pm 10.1$ \\
\hline ALT (IU/l) & $80.2 \pm 31.9^{\mathrm{a}}$ & $122.1 \pm 49.3^{\mathrm{a}}$ & $164.9 \pm 58.5^{\mathrm{a}}$ & $100.6 \pm 48.4^{\mathrm{a}}$ & $27.6 \pm 11.4$ \\
\hline ALP (IU/l) & $84.1 \pm 26.9$ & $80.5 \pm 24.2$ & $84 \pm 20.9$ & $82.9 \pm 25.5$ & $72.8 \pm 18.5$ \\
\hline Prothrombin time index ratio & $1.06 \pm 0.16$ & $1.02 \pm 0.09$ & $1.06 \pm 0.09$ & $1.05 \pm 0.14$ & $1.05 \pm 0.1$ \\
\hline Uric acid (mg/dl) & $5.62 \pm 1.23^{\mathrm{b}}$ & $5.75 \pm 1.37^{\mathrm{a}}$ & $5.4 \pm 1.39$ & $5.65 \pm 1.28^{\mathrm{a}}$ & $4.2 \pm 0.8$ \\
\hline Urea (mg/dl) & $23.12 \pm 11.08$ & $23.31 \pm 6.86$ & $20.9 \pm 5.7$ & $23 \pm 9.49$ & $22.2 \pm 7.86$ \\
\hline Creatinine (mg/dl) & $1.03 \pm 0.32$ & $0.99 \pm 0.2$ & $0.99 \pm 0.11$ & $1.01 \pm 0.27$ & $0.93 \pm 0.31$ \\
\hline $\mathrm{Na}(\mathrm{mEq} / \mathrm{l})$ & $138.9 \pm 4.7$ & $139.1 \pm 4.2$ & $139.1 \pm 3.7$ & $139 \pm 4.43$ & $138.3 \pm 3.86$ \\
\hline $\mathrm{K}(\mathrm{mEq} / \mathrm{l})$ & $4.3 \pm 0.51$ & $4.3 \pm 0.47$ & $4.5 \pm 0.63$ & $4.34 \pm 0.5$ & $4.18 \pm 0.45$ \\
\hline IL-4 (pg/ml) & $15.62 \pm 2.2$ & $14.87 \pm 3.35^{\mathrm{c}}$ & $12.46 \pm 2.73^{\mathrm{a}}$ & $15.13 \pm 2.78^{b}$ & $17.35 \pm 3.97$ \\
\hline IL-6 (pg/ml) & $4.69 \pm 0.81^{\mathrm{c}}$ & $5.43 \pm 0.79^{\mathrm{b}}$ & $5.71 \pm 1.08^{\mathrm{ad}}$ & $5.01 \pm 0.91^{\mathrm{b}}$ & $2.87 \pm 1.25$ \\
\hline IL-10 (pg/ml) & $9.84 \pm 2.57$ & $12.25 \pm 2.6$ & $12.2 \pm 1.97$ & $10.13 \pm 2.59$ & $9.9 \pm 2.49$ \\
\hline $\mathrm{TNF}-\alpha(\mathrm{pg} / \mathrm{ml})$ & $18.33 \pm 4.95$ & $24.33 \pm 4.32^{\mathrm{ad}}$ & $32.67 \pm 2.89^{\text {adf }}$ & $21.42 \pm 6.27^{\mathrm{a}}$ & $16.07 \pm 4.62$ \\
\hline TGF- $\beta 1(\mathrm{ng} / \mathrm{ml})$ & $9 \pm 5.49$ & $12.4 \pm 2.4^{\mathrm{ad}}$ & $17.8 \pm 3.46^{\text {adg }}$ & $10.75 \pm 5.2^{\mathrm{a}}$ & $6.74 \pm 4.57$ \\
\hline
\end{tabular}

Values are mean \pm SD of number of observation (n). Stages of liver disease based on clinical findings: I: mild; II: moderate; Stage III NAFLD patients are NASH patients

$P$ values: ${ }^{\mathrm{a}}<0.001,{ }^{\mathrm{b}}<0.01,{ }^{\mathrm{c}}<0.05$ compared to the Normal group; ${ }^{\mathrm{d}}<0.001,{ }^{\mathrm{e}}<0.05$ compared to group I of NAFLD patients; ${ }^{\mathrm{f}}<0.001$,

$\mathrm{g}<0.001$ compared to group II NAFLD patients

[19] since its first description up to this study. Though gender and weight status appear to modify the relationship between metabolic risk factors and NAFLD [20], Ludwig's pioneer report on NAFLD states that female gender is associated with fibrosis [2]. Although this may still be true [21], several epidemiological studies [22] including this one has shown that the prevalence of NAFLD is higher among males. Another cross-sectional study had shown that NAFLD was 3.5 times more common in males than in females among Asians [23] and was reported as a disease of young over-weight males among North Indian patients
[24]. But the major limitation to ascertain the role of female gender in this study is sample size.

Though liver biopsy remains the only reliable means to determine prognosis based on the severity of fibrosis [17], ethical consideration [4], expensive and invasive procedure associated with a number of complications and chances of sampling error [17] limited its applicability. In contrast, NAFLD diagnosed by ultrasound is associated with hypertriglyceridemia, impaired fasting glucose, silent myocardial ischemic pattern of ECG, obesity, and abnormal liver tests in adults. Among these factors, obesity was 
Table 3 Anthropometric profile, lipid profile, insulin resistance data and cytokines of male and female liver disease patients with their matched control

\begin{tabular}{|c|c|c|c|c|}
\hline & \multicolumn{2}{|l|}{ Male } & \multicolumn{2}{|l|}{ Female } \\
\hline & NAFLD $(n=89)$ & Normal $(n=45)$ & $\operatorname{NAFLD}(n=16)$ & Normal $(n=32)$ \\
\hline Age (years) & $41.2 \pm 10.04^{\mathrm{c}}(-11.9)$ & $46.8 \pm 11.79$ & $46.4 \pm 7.98(+6.6)$ & $43.5 \pm 10.04$ \\
\hline BMI $\left(\mathrm{kg} / \mathrm{m}^{2}\right)$ & $25.10 \pm 2.37^{\mathrm{a}}(+12.5)$ & $22.3 \pm 1.2$ & $26.6 \pm 2.49^{\mathrm{a}}(+15.6)$ & $23 \pm 1.39$ \\
\hline Waist/hip ratio & $1.04 \pm 0.03^{\mathrm{b}}(+1.9)$ & $1.02 \pm 0.01$ & $1.03 \pm 0.03(+0.98)$ & $1.02 \pm 0.03$ \\
\hline Cholesterol (mg/dl) & $213 \pm 45.6^{\mathrm{a}}(+30.5)$ & $163.2 \pm 26.1$ & $209.5 \pm 41^{\mathrm{a}}(+31.76)$ & $159 \pm 19.7$ \\
\hline HDL-Cholesterol (mg/dl) & $40 \pm 9.5(-8.88)$ & $43.9 \pm 10$ & $45.7 \pm 12.1(-3.78)$ & $47.5 \pm 8.1$ \\
\hline LDL-Cholesterol (mg/dl) & $134.9 \pm 38.9(+3.76)$ & $130 \pm 32$ & $142.6 \pm 29.3(+23.89)$ & $115.1 \pm 28.7$ \\
\hline VLDL-Cholesterol (mg/dl) & $36.2 \pm 17.1^{\mathrm{b}}(+36.6)$ & $26.5 \pm 10.1$ & $26.6 \pm 15(+11.76)$ & $23.8 \pm 10.2$ \\
\hline Triglyceride (mg/dl) & $180.9 \pm 60.6^{\mathrm{b}}(+31.56)$ & $137.5 \pm 53$ & $143.8 \pm 62.2(+22.07)$ & $117.8 \pm 47.7$ \\
\hline Glucose (mg/dl) & $114.8 \pm 42.2^{\mathrm{b}}(+21.48)$ & $94.5 \pm 13$ & $116.1 \pm 41.8^{\mathrm{c}}(+31.03)$ & $88.6 \pm 10.4$ \\
\hline Insulin $(\mu \mathrm{U} / \mathrm{ml})$ & $13.4 \pm 4.4^{\mathrm{c}}(+25.23)$ & $10.7 \pm 1.6$ & $14 \pm 6.5(+32.07)$ & $10.6 \pm 1.8$ \\
\hline HOMA-IR & $3.7 \pm 1.6^{\mathrm{a}}(+48)$ & $2.5 \pm 0.5$ & $3.9 \pm 2.16^{\mathrm{b}}(+69.56)$ & $2.3 \pm 0.4$ \\
\hline IL-4 (pg/ml) & $15.07 \pm 2.79(-8.99)$ & $16.56 \pm 3.9$ & $15.47 \pm 2.83(-16.28)$ & $18.48 \pm 3.85$ \\
\hline IL-6 (pg/ml) & $3.02 \pm 0.96(+7.85)$ & $2.8 \pm 0.56$ & $2.96 \pm 0.55(-0.32)$ & $2.97 \pm 0.65$ \\
\hline IL-10 (pg/ml) & $10.1 \pm 2.6(+4.77)$ & $9.64 \pm 2.61$ & $10.3 \pm 2.62(+0.2)$ & $10.28 \pm 2.29$ \\
\hline $\mathrm{TNF}-\alpha(\mathrm{pg} / \mathrm{ml})$ & $21.18 \pm 6.14^{\mathrm{b}}(+30.33)$ & $16.25 \pm 4.97$ & $22.79 \pm 7.02^{\mathrm{b}}(+44.05)$ & $15.82 \pm 4.16$ \\
\hline TGF- $\beta(\mathrm{ng} / \mathrm{ml})$ & $10.76 \pm 5.37^{\mathrm{a}}(+70.52)$ & $6.31 \pm 1.99$ & $10.7 \pm 4.28(+45.77)$ & $7.34 \pm 6.7$ \\
\hline
\end{tabular}

Values are mean \pm SD of number of observation $(n)$. Figures in the parentheses are \% increase $(+)$ or decrease $(-)$ compared to their respective normal group. $P$ values: a $<0.001, \mathrm{~b}<0.01, \mathrm{c}<0.05$ compared to their respective control

the only independent factor associated with ultrasounddiagnosed NAFLD [25]. Therefore, a scoring system with 6 independent indicators variables was considered to determine advanced liver fibrosis [17] in this study.

Insulin resistance (IR) may be defined as a condition in which higher than normal insulin concentrations are needed to achieve normal metabolic responses [1]. IR determined by the homeostasis model assessment (HOMA) is widely used in clinical and epidemiological studies, particularly with large patient populations [21, 26, 27]. We observed higher fasting serum insulin level in NAFLD patients with severity of the disease (Table 2), 73 patients (70\%) were categorized as insulin resistant whose HOMAIR was greater than 2.78 (corresponding to 75 th centile of normal subjects) following the methodology as described elsewhere [27], and $42 \%$ of the NAFLD patients fulfilled the minimum criteria for IRS in this study.

Insulin usually controls fuel homeostasis through the glucose uptake into peripheral tissues and by suppressing the release of stored lipids from adipose tissues [28]. Insulin activates lipoprotein lipase that promotes the catabolism of triglyceride-rich lipoproteins, such as chylomicrons and VLDL, and the clearance of LDL. Insulin also affect HDL metabolism through LCAT activation [29]. In agreement with earlier observations [30], elevated cholesterol, VLDLcholesterol, triglyceride and BMI in NAFLD patients compared to the normal subjects in this study, strengthening the association between overweight and the appearance of
NAFLD [31, 32]. Though accumulation of excess triglycerides in hepatocytes forms steatotic droplets in NAFLD [33] as observed in histologic finding (Fig. 1), mixed lipid disorders such as hyperlipidemia and hypertriglyceridemia are commonly associated with NAFLD, and the presence of lower HDL-cholesterol as observed in this study further increases the risk of NAFLD [34].

Insulin resistance (IR) is also associated with chronic lowgrade inflammation, and release several mediators from various cell types, including immune cells and adipocytes $[35,36]$. In addition, increased availability of lipids enhances lipid oxidation, and the end-product of lipid peroxidation is known to be pro-inflammatory mediators [3].

Pro-inflammatory cytokines TNF- $\alpha$ and IL-6 levels were elevated significantly in NAFLD patients with severity of the disease compared to the normal subjects in this study. TNF- $\alpha$ is known to activate intracellular signaling molecules, including stress related kinases such as Jun $\mathrm{N}$-terminal kinase and inhibitor kappa beta kinase beta, that make cells resistant to the actions of insulin [6]. Evidence suggests that the cellular mechanisms for insulin resistance also activate TNF- $\alpha$ production [37]. Raised serum TNF- $\alpha$ level has also been demonstrated in several studies of fatty liver disease [38, 39]. TNF- $\alpha$ activates harmful proatherogenic pathways partially through the reduction of HDLcholesterol, elevated expression of cholesterogenic genes, accompanied by an increase in potentially harmful precholesterol metabolites, and suppression of cholesterol 


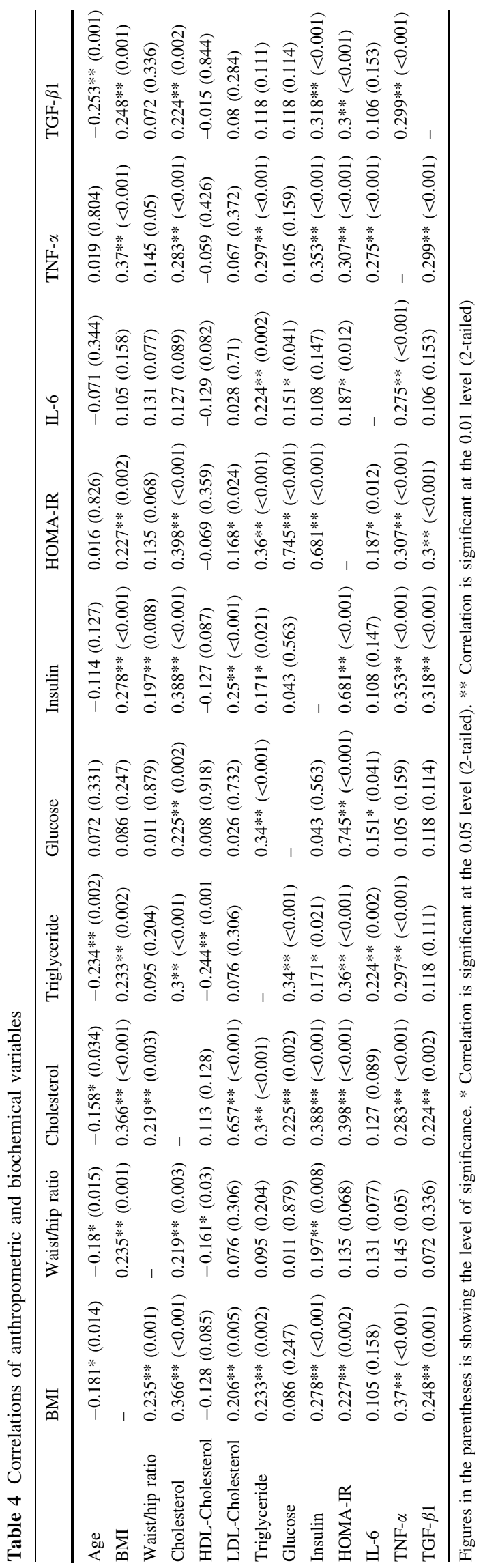

elimination [40]. TNF- $\alpha$ also stimulates hepatic fatty acid synthesis, increases serum triglyceride levels [41] and stimulates VLDL production from liver [42]. TNF- $\alpha$ can induce both hepatocyte cell death and hepatocyte proliferation [43], and is critically involved in the pathogenesis of liver fibrosis in NASH model [44].

IL-6 is a multifunctional cytokine that regulates immune responses, acute phase reactions and hematopoiesis, and may play a central role ranging from inflammation to host defense to tissue injury [45, 46]. Both TNF- $\alpha$ and IL-6 stimulate hepatic lipogenesis [47], associated with obesity and insulin resistance [48, 49], impairs insulin signaling [50, 51], and can alter insulin sensitivity by triggering different key steps in the insulin signaling pathway [52].

The anti-inflammatory cytokines, IL- 4 and IL-10 control the development of a human Th1-biased immune reaction [53]. IL-10 plays a protective role against liver damage from a number of aggressors. The inhibition of IL-10 promotes the expression of cytokines involved in inflammation, deterioration of insulin signal and activation of gluconeogenic and lipidogenic pathways [54]. However, IL-4 level decreased significantly in NAFLD patients compared to normal subjects, while IL-10 level remained unchanged in this study.

Thus NAFLD may be responsible for changing the balance between pro-inflammatory and anti-inflammatory cytokines. Pro-inflammatory cytokines enhances the expression of extracellular matrix and influences fibrogenic processes [5]. Transforming growth factor (TGF)- $\beta 1$, which plays a critical role in liver apoptosis, fibrogenesis [55], and collagen production [13] during chronic liver injury, was significantly elevated in NAFLD patients in this study.

In conclusion, NAFLD is associated with overweight, hyperlipidemia, diabetes mellitus and insulin resistance. The necroinflammatory component of NAFLD appears to be modulated by interactions among various factors. Proinflammatory cytokines play an important determinant between metabolic and liver disorders, and thereby causes insulin resistance and inflammation.

Acknowledgments Financial assistance received from Van Slyke Foundation-Critical and Point-of-Care Testing (VSF-CPOCT) Research Grant; American Association for Clinical Chemistry is gratefully acknowledged.

\section{References}

1. Bugianesi E, McCullough AJ, Marchesini G. Insulin resistance: a metabolic pathway to chronic liver disease. Hepatology. 2005; 42(5):987-1000.

2. Ludwig J, Viggiano TR, McGill DB, Ott BJ. Nonalcoholic steatohepatitis: Mayo Clinic experiences with a hitherto unnamed disease. Mayo Clin Proc. 1980;55:434-8. 
3. Das SK, Balakrishnan V, Mukherjee S, Vasudevan DM. Evaluation of blood oxidative stress related parameters in alcoholic liver disease and non-alcoholic fatty liver disease. Scand J Clin Lab Invest. 2008;68(4):323-34.

4. Das SK, Mukherjee S, Vasudevan DM. Non-alcoholic fatty liver diseases: an under recognized cause with emerging importance. Current Sci. 2006;90:659-65.

5. Fan JG, Zhu J, Li XJ, Chen L, Li L, Dai F, Li F, Chen SY. Prevalence of and risk factors for fatty liver in a general population of Shanghai, China. J Hepatol. 2005;43:508-14.

6. Diehl AM, Li ZP, Lin HZ, Yang SQ. Cytokines and the pathogenesis of non-alcoholic steatohepatitis. Gut. 2005;54(2):303-6.

7. Browning JD, Horton JD. Molecular mediators of hepatic steatosis and liver injury. J Clin Invest. 2004;114:147-52.

8. Day CP, James OF. Steatohepatitis - a tale of two hits. Gastroenterology. 1998;114:842-5.

9. McClain CJ, Mokshagundam SP, Barve SS, et al. Mechanisms of non-alcoholic steatohepatitis. Alcohol. 2004;34:67-79.

10. Ma KL, Ruan XZ, Powis SH, Chen Y, Moorhead JF, Varghese Z. Inflammatory stress exacerbates lipid accumulation in hepatic cells and fatty livers of apolipoprotein E knockout mice. Hepatology. 2008;48(3):770-81.

11. Drenick EJ, Fisler J, Johnson D. Hepatic steatosis after intestinal bypass - prevention and reversal by metronidazole, irrespective of protein-calorie malnutrition. Gastroenterology. 1982;82:53548.

12. Crews FT, Bechara R, Brown LA, Guidot DM, Mandrekar P, Oak S, Qin L, Szabo G, Wheeler M, Zou J. Cytokines and alcohol. Alcohol Clin Exp Res. 2006;30:720-30.

13. Cameron RG, Neuman MG. Novel morphologic findings in alcoholic liver disease. Clin Biochem. 1999;32(7):579-84.

14. Matthews DR, Hosker JP, Rudenski AS, Naylor BA, Treacher DF, Turner RC. Homeostasis model assessment: insulin resistance and beta cell function from fasting plasma glucose and insulin concentrations in man. Diabetologia. 1985;28: 412-9.

15. World Health Organization. Consultation. Definition, diagnosis and classification of diabetes mellitus and its complications. Geneva: World Health Organization; 1999. Report No. WHO/ $\mathrm{NCD} / \mathrm{NCS} / 99.2$.

16. Das SK, Mukherjee S, Pandey G, Balakrishnan V, Vasudevan DM. Clinicopathological spectrum of non-alcoholic fatty liver disease among patients in Kerala. Indian $\mathrm{J}$ Clin Biochem. 2009;24(2):155-8.

17. Angulo P, Hui JM, Marchesini G, Bugianesi E, George J, Farrell GC, et al. The NAFLD fibrosis score: a noninvasive system that identifies liver fibrosis in patients with NAFLD. Hepatology. 2007;45:846-54.

18. Ko GT, Wu MM, Tang J, Wai HP, Chan CH, Chen R. Body mass index profile in Hong Kong Chinese adults. Ann Acad Med Singapore. 2001;21(1):17-26.

19. Falck-Ytter Y, Younossi ZM, Marchesini G, McCullough AJ. Clinical features and natural history of nonalcoholic steatosis syndromes. Semin Liver Dis. 2001;21(1):17-26.

20. Lee K, Sung JA, Kim JS, Park TJ. The roles of obesity and gender on the relationship between metabolic risk factors and nonalcoholic fatty liver disease in Koreans. Diabetes Metab Res Rev. 2009;25(2):150-5.

21. Marchesini G, Bugianesi E, Forlani G, Cerrelli F, Lenzi M, Manini R, et al. Non alcoholic fatty liver, Steatohepatitis and the metabolic syndrome. Hepatology. 2003;37:917-23.

22. Wilfred de Alwis NM, Day CP. Genetics of alcoholic liver disease and nonalcoholic fatty liver disease. Semin Liver Dis. 2007;27:44-54.

23. Weston SR, Leyden W, Murphy R, Bass NM, Bell BP, Manos MM, Terrault NA. Racial and ethnic distribution of nonalcoholic fatty liver in persons with newly diagnosed chronic liver disease. Hepatology. 2005;41:372-9.

24. Madan K, Batra Y, Gupta SD, Chander B, Rajan KD, Tewatia MS, et al. Non-alcoholic fatty liver disease may not be a severe disease at presentation among Asian Indians. World J Gastroenterol. 2006;12:3400-5.

25. Lee S, Jin Kim Y, Yong Jeon T, Hoi Kim H, Woo Oh S, Park Y, Soo Kim S. Obesity is the only independent factor associated with ultrasound-diagnosed non-alcoholic fatty liver disease: a cross-sectional case-control study. Scand J Gastroenterol. 2006;41(5):566-72.

26. Marchesini G, Brizi M, Morselli-Labate AM, Bianchi G, Bugianesi E, McCullough AJ, et al. Association of non alcoholic fatty liver disease with insulin resistance. Am J Med. 1999;107: $450-5$.

27. Chitturi S, Abeygunasekera S, Farrell GC, Holmes-Walker J, Hui JM, Fung C, et al. NASH and insulin resistance: insulin hypersecretion and specific association with the insulin resistance syndrome. Hepatology. 2002;35:373-9.

28. Muoio DM, Negward CB. Molecular and metabolic mechanisms of insulin resistance and $\beta$-cell failure in type 2 diabetes. Nat Rev Mol Cell Biol. 2008;9:193-205.

29. Verges B. Insulin sensitiviy and lipids. Diabetes Metab. 2001; 27(2 Pt 2):223-7.

30. Kojima H, Sakurai S, Uemura M, Takekawa T, Morimoto H, Tamagawa Y, Fukui H. Difference and similarity between nonalcoholic steatohepatitis and alcoholic liver disease. Alcohol Clin Exp Res. 2005;29(Suppl 12):259S-63S.

31. Ratziu V, Giral P, Charlotte F, Bruckert E, Thibault V, Theodorou I, et al. Liver fibrosis in overweight patients. Gastroenterology. 2000;118:1117-23.

32. Loguercio C, De Girolamo V, de Sio I, Tuccillo C, Ascione A, Baldi F, et al. Non-alcoholic fatty liver disease in an area of southern Italy: main clinical, histological, and pathophysiological aspects. J Hepatol. 2001;35:568-74.

33. Tiniakos DG, Vos MB, Brunt EM. Nonalcoholic fatty liver disease: pathology and pathogenesis. Annu Rev Pathol. 2010;5:145-71.

34. Clark JM, Diehl AM. Nonalcoholic fatty liver disease: an underrecognized cause of cryptogenic cirrhosis. JAMA. 2003; 289(22):3000-4.

35. Tilg H, Moschen AR. Inflammatory mechanisms in the regulation of insulin resistance. Mol Med. 2008;14(3-4):222-31.

36. Polyzos SA, Kountouras J, Zavos C. Nonalcoholic fatty liver disease: the pathogenetic roles of insulin resistance and adipocytokines. Curr Mol Med. 2009;9(3):299-314.

37. Kim JK, Kim YJ, Fillmore JJ, Chen Y, Moore I, Lee J, et al. Prevention of fat-induced insulin resistance by salicylate. J Clin Invest. 2001;108:437-46.

38. Kuglemas M, Hill D, Vivian B, Marsano L, McClain C. Cytokines and NASH: a pilot study of the effects of lifestyle modification and vitamin E. Hepatology. 2003;38:413-9.

39. Wigg AJ, Roberts-Thomson IC, Dymock RB, McCarthy PJ, Grose RH, Cummins AG. The role of small intestinal bacterial overgrowth, intestinal permeability, endotoxaemia, and tumor necrosis factor alpha in the pathogenesis of non-alcoholic steatohepatitis. Gut. 2001;48:206-11.

40. Fon Tacer K, Kuzman D, Seliskar M, Pompon D, Rozman D. TNF-alpha interferes with lipid homeostasis and activates acute and proatherogenic processes. Physiol Genomics. 2007;31(2): 216-27.

41. Feingold KR, Soued M, Serio MK, Adi S, Moser AH, Grunfeld C. The effect of diet on tumor necrosis factor stimulation of hepatic lipogenesis. Metabolism. 1990;39(6):623-32.

42. Grunfeld C, Feingold KR. Tumor necrosis factor, interleukin, and interferon induced changes in lipid metabolism as part of host defense. Proc Soc Exp Biol Med. 1992;200:224-7. 
43. Wullaert A, van Loo G, Heyninck K, Beyaert R. Hepatic tumor necrosis factor signaling and nuclear factor-kappaB: effects on liver homeostasis and beyond. Endocr Rev. 2007;28(4):365-86.

44. Tomita K, Tamiya G, Ando S, Ohsumi K, Chiyo T, Mizutani A, et al. Tumour necrosis factor alpha signalling through activation of Kupffer cells plays an essential role in liver fibrosis of nonalcoholic steatohepatitis in mice. Gut. 2006;55(3):415-24.

45. Papanicolaou DA, Wilder RL, Manolagas SC, Chrousos GP. The pathophysiologic roles of interleukin- 6 in human disease. Ann Intern Med. 1998;128:127-37.

46. Sehgal PB, Greininger G, Tosato G. Regulation of the acute phase and immune responses: interleukin 6. Ann NY Acad Sci. 1989;557:1-583.

47. Brass EP, Vetter WH. Interleukin-6, but not tumour necrosis factor-alpha, increases lipogenesis in rat hepatocyte primary cultures. Biochem J. 1994;301(Pt 1):193-7.

48. Fernandez-Real JM, Ricart W. Insulin resistance and chronic cardiovascular inflammatory syndrome. Endocr Rev. 2003;24: 278-301.

49. Kim HJ, Higashimori T, Park SY, Choi H, Dong J, Kim YJ, et al. Differential effects of interleukin-6 and -10 on skeletal muscle and liver insulin action in vivo. Diabetes. 2004;53(4):1060-7.
50. Hotamisligil GS. Inflammatory pathways and insulin action. Int $\mathbf{J}$ Obes Relat Metab Disord. 2003;27(Suppl 3):S53-5.

51. Senn JJ, Klover PJ, Nowak IA, Mooney RA. IL-6 induces insulin resistance in hepatocytes. Diabetes. 2002;51:3391-9.

52. Bastard JP, Maachi M, Lagathu C, Kim MJ, Caron M, Vidal H, Capeau J, Feve B. Recent advances in the relationship between obesity, inflammation, and insulin resistance. Eur Cytokine Netw. 2006;17(1):4-12.

53. Skapenko A, Niedobitek GU, Kalden JR, Lipsky PE, SchulzeKoops H. Generation and regulation of human Th1-biased immune responses in vivo: a critical role for IL-4 and IL-10. J Immunol. 2004;172(10):6427-34.

54. Cintra DE, Pauli JR, Araújo EP, Moraes JC, de Souza CT, Milanski $\mathrm{M}$, et al. Interleukin-10 is a protective factor against diet-induced insulin resistance in liver. J Hepatol. 2008;48(4): 628-37.

55. Tarantino G, Conca P, Riccio A, Tarantino M, Di Minno MN, Chianese D, et al. Enhanced serum concentrations of transforming growth factor-beta1 in simple fatty liver: is it really benign? J Transl Med. 2008;6:72. 